\title{
Adaptasi alat ukur Munroe Multicultural Attitude Scale Questionnaire versi Indonesia
}

\author{
Intan Permatasari, Nesya Adira, Mirra Noor Milla*, Nudzran Yusya, \\ Selfiyani Lestari, dan Boma Baswara \\ Fakultas Psikologi, Universitas Indonesia, Depok, Jawa Barat
}

\begin{abstract}
Abstrak
Usaha adaptasi alat ukur multikulturalisme menjadi penting karena terdapat perbedaan dalam persepsi multikulturalisme di negara-negara barat dan Indonesia. Jika multikulturalisme di negara-negara barat lebih merujuk pada perbedaan warna kulit, di Indonesia multikulturalisme dapat dikatakan lebih dinamis, yaitu merujuk pada perbedaan suku. Oleh karena itu, diperlukan adanya alat ukur yang dapat digunakan untuk mengukur konstruk multikulturalisme. Penelitian ini dilakukan demi tujuan tersebut, dengan cara mengadaptasi alat ukur Munroe Multicultural Attitude Scale Questionnaire (MASQUE). Pemilihan MASQUE sebagai alat ukur yang diadaptasi karena MASQUE dapat mengukur sikap terhadap multikulturalisme pada sampel yang lebih luas. Adaptasi MASQUE dilakukan melalui tahap penerjemahan, penerjemahan ulang, pengujian validitas, serta pengujian reliabilitas. Pengujian validitas alat ukur MASQUE versi Indonesia dilakukan menggunakan Confirmatory Factor Analysis (CFA), sedangkan pengujian reliabilitas alat ukur dilakukan dengan menggunakan Cronbach-Alpha. Hasil adaptasi alat ukur yang diuji pada 1393 responden menunjukkan bahwa tiga dimensi (pengetahuan, tindakan, dan kepedulian) dalam kuesioner ini reliabel, tetapi memiliki validitas konstruk yang kurang baik. Kesimpulannya, alat ukur ini dapat digunakan untuk mengukur multikulturalisme di Indonesia, dengan catatan menghapus beberapa item alat ukur asli yang sulit dipahami dalam konteks Indonesia.
\end{abstract}

Kata kunci: multikulturalisme, adaptasi, skala, versi Indonesia

\begin{abstract}
The effort to adapt multiculturalism measures is important due to differences in perceptions of multiculturalism among Western countries and Indonesia. When multiculturalism in Western refers more to racial differences, in Indonesia, multiculturalism is more dynamic and refers more to ethnicity. Therefore, we need the existence of a measuring tool that can be used to measure the construct of multiculturalism. This research was carried out to achieve that very objective, by adapting the Munroe Multicultural Attitude Scale Questionnaire (MASQUE) measurement tool. MASQUE is chosen because MASQUE is believed to be able to measure attitude towards multiculturalism on a wider range of samples. MASQUE adaptation was conducted through translation, back translation, validity testing, and reliability testing. The validity testing of the Indonesian version of MASQUE was carried out using Confirmatory Factor Analysis (CFA), while the reliability testing of the measuring instrument was carried out using Cronbach Alpha. The adaptation results of the measuring instrument tested in 1393 respondents indicated that this questionnaire with three dimensions of knowledge, care, and act towards multiculturalism although reliable, does not have good construct validity. Therefore, we concluded that the questionnaire could be used to measure multiculturalism in Indonesia when several items in the original questionnaire that were too difficult to be understood in the Indonesian context were excluded.
\end{abstract}

Keywords: multiculturalism, adaptation, scale, Indonesian

\section{Pendahuluan}

Indonesia merupakan negara yang terdiri dari berbagai macam kebudayaan. Badan Pusat Statistik (BPS) (2015) menjelaskan bahwa Indonesia memiliki 633 kelompok suku besar. Dalam kehidupan masyarakat yang multikultural tersebut, sangat penting untuk memahami keadaan hubungan antara

Naskah masuk: 22 Agustus 2019

Naskah diterima: 27 April 2020 berbagai kelompok kebudayaan tersebut. Studi mengenai sikap terhadap multikultural isme dalam psikologi sosial menjadi elemen kunci dalam usaha memperdalam pemahaman tersebut (Berry \& Kalin, 1995).

Multikulturalisme sangat penting bagi kehidupan bermasyarakat karena beberapa riset menunjukkan bahwa tingginya multikulturalisme

* Fakutas Psikologi, Universitas Indonesia, Kampus UI Depok, Jawa Barat, Indonesia, 16424 E-mail:mnmilla@gmail.com 
berkaitan erat dengan menurunnya tingkat prejudice (Rios \& Wynn, 2016) dan bias rasial individu (Richeson \& Nisbaum, 2004) serta bisa memicu hubungan yang lebih positif antar kelompok (Sasaki \& Vorauer, 2013). Bagi bangsa Indonesia, yang terdiri atas banyak suku dan budaya multikulturalisme menjadi lebih penting untuk membuat Indonesia tidak terpecah belah.

Oleh karena itu, sangat penting bagi warga negara untuk mengadopsi multikulturalisme dalam kehidupan sehari-hari. Namun menurut Parker (2014; 2017), Indonesia termasuk negara yang masyarakatnya belum menerapkan mul tikulturalisme. Selain itu, para pembuat kebijakan publik pun belum menerapkan konsep multikulturalisme ini dalam kebijakan yang mereka buat. Oleh karena itu, penting bagi kita untuk mengetahui tingkat multikulturalisme masyarakat saat ini agar bisa memetakan kelompokkelompok masyarakat mana yang memiliki tingkat multikulturalisme yang rendah dan bisa mengancam. Selain itu, penting juga untuk mengetahui tingkat multikulturalisme para calon pembuat kebijakan publik agar kebijakan publik yang dihasilkannya lebih bisa merepresentasikan semua kelompok yang ada di masyarakat sehingga bisa tercipta keharmonisan di antara berbagai kelompok dan etnis di indonesia. Untuk dapat mengetahui tingkat multikulturalisme masyarakat dan para calon pembuat kebijakan publik, maka diperlukan alat untuk mengukur tingkat multikulturalisme. Oleh karena itu, penulis melakukan adaptasi alat ukur MASQUE.

Menurut Benet-Martinez dan Hong (2014) ada delapan alat ukur yang bisa digunakan untuk mengukur tingkat multikulturalisme, yaitu: Multicultural Attitude Scale, Multicultural Awareness to School Environment, Multicultural AwarenessKnowledge-Skills Survey (MAKSS), Multicultural Competency Scale, Multicultural Counseling Knowledge and Awareness Scale (MCKAS), Multicultural Efficacy Scale (MES), Multicultural Ideology Scale (MIS), dan Munroe Multicultural Attitude Scale Questionnaire (MASQUE).

Dari tujuan alat tersebut, sangat sedikit al at ukur yang mengukur perilaku dan sikap multikulturalisme secara bersamaan. Selain itu, tiga dari alat ukur tersebut yaitu MES, MAKSS, dan MCKAS hanya mengukur pada kelompok masyarakat yang sangat spesifik seperti guru dan konselor saja sehingga jika ingin digunakan untuk mengukur multikulturalisme maka diperlukan usaha yang lebih untuk melakukan penyesuaian kata-kata dari item pada skala. Selain itu, ada juga alat ukur lainnya yang hanya bisa digunakan pada lingkungan tertentu yaitu Multicultural Awareness to School Environment yang hanya bisa digunakan di sekolah.

MASQUE berbeda dari beberapa alat ukur yang telah disebutkan. Alat ukur ini dapat digunakan untuk masyarakat luas karena tidak terlalu menggunakan kata atau kalimat yang spesifik mengenai lingkungan dan populasi. Skala lainnya, yakni Multicultural Competency Scale tidak dipilih karena alat ukur ini tidak menyertakan hasil pengukuran reliabilitas sehingga reliabilitas alat ukur tidak diketahui. Penulis juga tidak memilih Multicultural Attitude Scale karena skala tersebut lebih menyorot mengenai imigran sedangkan di Indonesia permasalahan utama bukan mengenai imigran, tetapi lebihkepada perbedaan etnis.

Alasan lain ulat ukur lainnya tidak dipakai ialah karena terlalu menekankan ideologi politik dalam mengukur multikulturalisme. Konsep multikulturalisme didefinisikan secara berbeda-beda, tergantung konteks, baik sebagai suatu diskursus, kebijakan atau suatu tindakan (Hoon, 2017). Kebanyakan alat ukur terkait mengukur sikap terhadap multikulturalisme sebagai suatu ideologi atau suatu fenomena sosial (Seperti: "Saya rasa terlalu banyak imigran yang tinggal di [negara] ini") (Stuart \& Ward, 2018). Konsep multikulturalisme memang berasal dari Barat yang muncul dari proses migrasi. Sebaliknya, Indonesia merupakan negara yang dasarnya memang multikultural. Masyarakat kita telah memiliki konsep multikulturalisme yang menjadi bagian dari kearifan lokal "Bhinneka Tunggal Ika". MASQUE merupakan salah satu alat ukur multikulturalisme yang tidak terbatas pada konsep penerimaan multikulturalisme sebagai ideologi, tetapi lebih mempertimbangkan multikulturalisme dalam domain sikap dan perilaku individu sehari-hari.

MASQUE yang dibuat oleh Arnold Munroe tahun 2006 merupakan alat ukuryang dibangunatas dasar kebutuhan akan suatu instrumen yang secara psikometris dapat mengukur tingkat sikap terhadap multikulturalisme. Pada saat alat ukur tersebut dibuat, kebanyakan alat ukur multikulturalisme dibuat secara spesifik untuk digunakan pada ranah tertentu, seperti konseling, edukasi guru, dan kesehatan (Amin, Wahab, \& Aziz, 2012). MASQUE dibangun dengan tujuan mengukur perubahan sikap terhadap multikulturalisme pada mahasiswa, tetapi dapat digunakan untuk sampel yang lebih luas. Hal ini karena dimensi yang diukur merupakan tiga faktor yang dapat mendasari sikap dal am model $A B C$ (Affective, Behavioral, Cognitive) yang dikembangkan oleh Fishbein dan Ajzen (1975), yaitu pengetahuan dan kepercayaan yang dimiliki, ikatan emosional terkait pengetahuan dan kepercayaan tersebut, dan perilaku yang ditunjukkan seseorang. Adaptasi alat ukur MASQUE menjadi penting karena terdapat perbedaan dalam persepsi multikulturalisme di negara-negara barat dan negara-negara Asia termasuk Indonesia (Hoon, 2017).

Jika multikulturalisme dinegara-negarabarat lebih merujuk pada perbedaan warna kulit, di Indonesia multikulturalisme dapat dikatakan lebih dinamis, yaitu merujuk pada perbedaan suku. Salah satu konflik antar suku yang paling besar di 
Indonesia adalah konflik Sampit yang terjadi antara suku Dayak dan pendatang dari Madura, dan memuncak pada tahun 2001. Pada puncaknya, sekitar 500 orang dari suku Madura meninggal dunia (BBC, 2004). Oleh karena itu, alat ukur MASQUE penting untuk diadaptasi di Indonesia agar dapat lebih memahami cara-cara yang dapat digunakan dalam usaha menjembatani hubungan antara suku dan menghindari konflik.

MASQUE dikembangkan berdasarkan model yang diungkapkan oleh Banks (1999). Banks mengembangkan model transformatif yang dapat digunakan untuk memahami perubahan sikap dan perilaku dalam ranah pendidikan. Banks dan Banks (1995) menggunakan konsep pendidikan multikultural sebagai suatu rancangan untuk memperkenalkan pentingnya memahami dan menilai penting suatu perbedaan budaya (Munroe, 2006). Dalam modelnya yang digunakan dalam pendidikan multikultural, Munroe (2006) menjelaskan bahwa Banks memiliki kesesuaian dengan taksonomi Bloom yang digunakan sebagai dasar pertimbangan dalam perubahan perilaku dan sikap serta pengukuran sikap. Akhirnya MASQUE dikembangkan berdasarkan model yangdikembangkan Banks. Sebab, dalam model tersebut diungkapkan bahwa dalam memahami suatu sikap individu terhadap suatu objek maka terdapat tiga komponen yang harus diperhatikan. Pengukuran terhadap tiga komponen ini dalam dipandang penting oleh Munroe untuk memahami sikap individu. Komponen tersebut terdiri dari know (pengetahuan), care (kepedulian), dan act (tindakan). Komponen know (pengetahuan) menekankan pada pengetahuan individu terhadap objek, komponen care (kepedulian) menekankan pada penilaian positif atau negatif terhadap objek, dan komponen act (tindakan) menekankan pada tindakan yang diambil oleh individu terhadapobjek (Munroe, 2006). Munroe (2006) mengembangkan skala sikap terhadap multikultural dengan membagi skalanya ke dalam tiga komponen yang diungkapkan Bank yaitu know, care, dan act. Alat ukur ini memiliki 18 item dengan pembagiannya yaitu 7 item menggambarkan dimensi know, 6 item menggambarkan dimensi care, dan 5 item menggambarkan dimensi act (setiap dimensi berkorelasi satu sama lainnya). Skala ini reliabel secara konsistensi internal dengan besaran koefisien Cronbach Alpha yaitu 0,80. Sedangkan konsistensi internal untuk masing-masing dimensi berbeda yaitu dimensi know sebesar 0,70, dimensi care sebesar 0,70, dan dimensi actsebesar 0,58.

Kelebihan MASQUE yaitu memiliki korelasi yang rendah dengan social desirability yang diuji melalui pengkorelasian hasil pengukuran MASQUE dan Marlowe-Crowne Scores (Thornson \& Ross, 2008). Munroe (2006) menjelaskan bahwa alat ukur yang dikembangkan oleh dirinya memilikikelebihan karena melibatkan ketiga komponen dalam sikap untuk menyimpulkan sikap individu. Selain itu,
MASQUE merupakan skala yang memiliki struktur faktor yang tergolong baik dan menunjukkan validitas konstruk paling kuat di antara skala sikap multikultural lain (Jensen, 2016). Oleh karena itu, MASQUE digunakan dalam berbagai ranah penelitian seperti bidang pendidikan (Enger \& Lajimodiere, 2011; Van Camp \& Baugh, 2016), kompetensi lintas budaya (Schroeder, Plata \& Fullwood, 2013), dan perilaku konsumen (Spiers, Gundala, \& Singh, 2014).

\section{Studi 1}

\section{Metode Penelitian}

\section{Tahap 1 - Penerjemahan MASQUE}

Penelitian tahap 1 dilakukan dengan mengacu kepada proses adaptasi bahasa dan budaya alat ukur y ang dikemukakan oleh Beaton, dkk. (2000). Pertama, ketiga orang penerjemah (minimal dua orang) secara terpisah menerjemahkan MASQUE dari bahasa Inggris ke bahasa Indonesia. Penelitian ini melibatkan tiga orang penerjemah. Penerjemah pertama adalah seorang penerjemah profesional yang memiliki gelar sarjana sastra inggris dengan skor IELTS 7,5. Penerjemah kedua adalah sarjana psikologi dengan pengalaman mengonstruksi alat ukur untuk tujuan akademik maupun praktis dan memiliki skor TOEFL 557. Orang ketiga adalah lulusan program sarjana kelas khusus internasional yang bukan dari latar belakang ilmu psikologi dengan skor TOEFL 560 yang terbiasa menulis, membaca, dan berkomunikasi dalam bahasa Inggris. Ketiga orang penerjemah yang memiliki skor TOEFL dan/atau IELTS di atas rata-rata serta dari latar belakang psikologi dan non-psikologi secara terpisah menerjemahkan MASQUE.

Kedua, ketiga hasil terjemahan dilihat kesetaraannya melalui diskusi tim peneliti. Langkah ini menghasilkan draf MASQUE versi bahasa Indonesia. Ketiga, draf MASQUE versi bahasa Indonesia diterjemahkan ulang ke dalam bahasa Inggris yang dilakukan oleh dua orang penerjemah yang memiliki pengalaman lebih dari sepuluh tahun tinggal di Australia dan Amerika sehingga bahasa Inggris merupakan bahasa ibu mereka. Kemudian hasil terjemahan ulang ke dalam bahasa Inggris dilihat kesesuaian maknanya dengan cara membandingkannya dengan MASQUE versi asli. Item terjemahan bahasa Indonesia yang dianggap menyimpang dari makna bahasa Inggris dicari kata lain yang sesuai dengan definisi konstruk masing-masing dimensi MASQUE.

Keempat, draf MASQUE bahasa Indonesia yang sudah diperkaya dengan perbandingan dari hasil penerjemahan ulang diberikan kepada tiga orang ahli dalam bidang multikulturalisme untuk mendapatkan masukan secara kesetaraan konseptual terkait apakah sebuah istilah memiliki makna yang 
sama dalam budaya yang berbeda dan kesetaraan semantik terkait apakah sebuah istilah diterjemahkan ke dalam pengertian yang sama secara gramatikal (Beaton, dkk., 2000). Adapun tiga ahli tersebut terdiri dari dua pengajar di Fakultas Psikologi Universitas Indonesia yang mendalami topik-topik terkait lintas budaya dan satu mahasiswa doktoral psikologi sosial di Universitas Indonesia yang aktif meneliti mengenai multikulturalisme. Ketiga orang tersebut memberikan masukan konstruktif untuk item final dari hasil terjemahan awal, sintesis, dan penerjemahan ulang. Para ahli diberikan lampiran proses penerjemahan dari awal hingga akhir agar mereka memahami alasan keputusan akhir tim peneliti dalam sintesis hasil terjemahan dari tiga orang yang berbeda. Masukan dari para ahli didiskusikan dan ditindaklanjuti untuk merevisi beberapa item.

Kelima, MASQUE versi bahasa Indonesia yang dihasilkan dari empat langkah diatas ini disajikan kepada 1400 orang dengan metode random sampling melalui platform google form untuk melakukan pretest. Namun, tujuh orang tidak bersedia mengisi kuesioner sehingga total partisipan yang berpartisipasi adalah 1393 orang.

\section{Tahap 2 - Uji kesesuaian model}

Penelitian tahap 2 bertujuan untuk menguji kesesuaian model pengukuran tiap dimensi MASQUE versi bahasa Indonesia. Adaptasi alat ukur MASQUE diuji reliabilitasnya melalui pengujian konsistensi internal antar item dengan cronbach alpha. Sebab, menimbang akan dilakukannya satu kali pengukuran dan item memuat lebih dari satu pilihan jawaban. Sedangkan validitasnya diuji dengan menggunakan validitas konstruk, khususnya melalui confirmatory factor analysis. Sebab, pengujian ini dimaksudkan untuk menguji validitas bangunan teoritik dari masing-masing item sebagai variabel laten dari setiap dimensi yang mengukur multikulturalisme. Pengujian validitas dan reliabilitas dilakukan dengan menggunakan software $\mathrm{R}$ versi 3.6.0. Sebelum melakukan uji validitas dan reliabilitas, dilakukan uji normalitas terlebih dahulu untuk menentukan estimator yang digunakan dalam proses Confirmatory Factor Analysis (CFA).

MASQUE terdiri dari tiga dimensi, yaitu know (pengetahuan), care (kepedulian), dan act (tindakan). Dimensi know terdiri dari tujuh item, care terdiri dari enam item, dan act terdiri dari lima item. Model utama ini selanjutnya disebut sebagai M1. Langkah pengujian kesesuaian M1 adalah sebagai berikut; (1) uji normalitas terlebih dahulu untuk menentukan estimatoryang digunakan dalam proses CFA; (2) Uji validitas M1 dengan analisis CFA dan analisis reliabilitas dengan menggunakan Cronbach-Alpha terhadap skala MASQUE versi bahasa Indonesia; (3) M1 belum memenuhi kriteria fit sehingga peneliti menyusun model baru yang disebut sebagai M2; (4) Analisis CFA untuk menguji validitas M2 dan analisis reliabilitas dengan menggunakan Cronbach-Alpha.

\section{Hasil Penelitian}

Dari 1400 responden kuesioner, tujuh responden dikeluarkan dari analisis karena tidak bersedia melanjutkan pengisian sehingga diperoleh jumlah responden akhir 1393 orang. Kebanyakan responden berjenis kelamin perempuan $(n=1294,92,9 \%)$. Rerata usia responden 21,36 tahun dengan responden termuda berusia 14 tahun dan tertua berusia 41 tahun. Persebaran etnis responden terbanyak dari etnis Jawa ( $n=686,49,2 \%)$ diikuti Sunda $(n=302$, $21,7 \%$ ), dan sisanya berasal dari etnis-etnis yang ada di Indonesia termasuk Betawi, Batak, Bugis-Makassar, Tionghoa, dan Minang. Mayoritas responden beragama Islam (n=1315, 94,4\%) dan melaporkan penggunaan Bahasa Indonesia dalam kesehariannya ( $n=1274,91,5 \%)$. Adapun sebaran status sosioekonomi responden penelitian ini memiliki tingkat pendidikan yang cukup tinggi, dengan 57,6\% dari responden telah menyelesaikan SMA, kemudian 34\% responden telah menyelesaikan $\mathrm{S} 1$, dan 50,2\% merupakan mahasiswaS1.

Hasil pengujian normalitas menunjukkan bahwa data tidak normal $(\mathrm{p}<0,001)$, sehingga diputuskan menggunakan estimator WLSMV untuk validitas alat ukur MASQUE versi Indonesia dengan menggunakan CFA. CFA dilakukan dengan structural equation modeling (SEM) menggunakan package lavaan ver 0.5-22 pada program $R$ versi 3.6.0. Indeks fit yang digunakan sebagai kriteria penentu fit atau tidaknya model adalah: CFI > 0,95; RMSEA < 0,06 dan SRMR < 0,08 (Hu \& Bentler, 1999).

Hasil analisis menunjukkan model dengan tiga faktor yang sesuai dengan teori pada alat ukur asli ternyata tidak memiliki validitas konstruk yang baik karena tidak memenuhi tiga indikator yang menyatakan kesesuaian model $\left(\chi^{2}\right.$ (1393) = 2612,$814 ; \mathrm{p}<0,001 ; \mathrm{CFI}=0,89 ; \mathrm{RMSEA}=0,90$ [90\% CI 0,086; 0,094],SRMR =0,093) meskipun reliabilitas skala telah cukup baik (alpha $=0,84)$. Reliabilitas untuk tiap dimensi bagus kecuali satu dimensi, yakni dimensi ACT. Setelah dilihat angka muatan faktor untuk tiap item, ternyata ada empat item yang memiliki korelasi negatif. Sehingga, diputuskan untuk menghapus item tersebut dan melakukan analisa ulang tanpa menyertakan item-item ters ebut. Oleh karena itu, dilakukan analisa ulang yang tidak menyertakan keempat item tersebut.

Hasil tabel 2 menunjukkan bahwa modelnya fit karena memenuhi tiga indikator yang menyatakan kesesuaian model yaitu CFI, SMRM, dan RMSEA ( $\chi^{2}$ $(1393)=624,729, \mathrm{p}<0,001, \mathrm{CFI}=0,980, \mathrm{RMSEA}=$ $0,044[90 \%$ CI 0,039,0,050], SRMR = 0,054) dengan reliabilitas yang baik (alpha $=0,83$ ). Faktor loading 
dari masing-masing item bagus karena melebihi standar $>0,3$. Selain itu, tiap dimensi dalam skala juga reliabel dengan rentang nilai Cronbach-Alpha antara $0,753-0,900$.

Tabel 1

Muatan Faktor Skala MASQUE versi Indonesia 3 Dimensi $(N=1393)$

\begin{tabular}{|c|c|c|}
\hline Item/Dimensi & $\begin{array}{l}\text { Muatan } \\
\text { Faktor }\end{array}$ & $\begin{array}{c}\text { Cronbach } \\
\text { Alpha }\end{array}$ \\
\hline Dimensi: Pengetahuan & & 0,839 \\
\hline 1. Saya menyadari bahwa rasisme terjadi di sekitar saya & 0,523 & \\
\hline 2. Saya menyadari adanya batasan sosial & 0,557 & \\
\hline 3. Saya memahami bahwa kepercayaan agama bisa berbeda-beda & 0,834 & \\
\hline 4. Saya memahami bahwa kecenderungan seksual bisa berbeda-beda & 0,708 & \\
\hline 5. Saya memahami adanya ketidakadilan terhadap perempuan & 0,689 & \\
\hline 6. Saya menerima kenyataan bahwa terdapat bahasa selain bahasa Indonesia yang digunakan & 0,800 & \\
\hline 7. Saya tidak mengerti kenapa masyarakat dari budaya lain berperilaku secara berbeda & $-0,286$ & \\
\hline Dimensi: Kepedulian & & 0,791 \\
\hline 8. Saya menganggap penting untuk menghormati perbedaan agama & 0,897 & \\
\hline 9. Saya peka terhadap perbedaan perilaku berdasarkan budaya & 0,800 & \\
\hline 10. Saya prihatin secara emosional terhadap ketidakadilan etnis & 0,844 & \\
\hline 11. Saya peka terhadap perbedaan status ekonomi & 0,790 & \\
\hline 12. Saya tidak peka terhadap penggunaan bahasa selain bahasa Indonesia & $-0,1501$ & \\
\hline $\begin{array}{l}\text { 13. Status sosial seseorang tidak mempengaruhi perlakuan saya terhadap orang lain } \\
\text { Dimensi: Tindakan }\end{array}$ & 0,671 & 0,523 \\
\hline 14. Saya tidak melakukan apa-apa untuk menghentikan ketidakadilan berdasarkan etnis & 0,284 & \\
\hline 15. Saya secara aktif menantang ketidakadilan terhadap perempuan & $-0,593$ & \\
\hline 16. Saya tidak melakukan apa-apa untuk secara aktif melawan prasangka beragama & 0,250 & \\
\hline $\begin{array}{l}\text { 17. Saya secara sopan membantu orang lain mengatasi batasan bahasa yang menghambat } \\
\text { komunikasi }\end{array}$ & $-0,771$ & \\
\hline $\begin{array}{l}\text { 18. Saya tidak melakukan apa pun ketika menyaksikan perlakuan tidak adil berdasarkan } \\
\text { orientasi seksual }\end{array}$ & 0,109 & \\
\hline
\end{tabular}

* item bermuatan negatif sehingga dihapus dari analisis kedua

Tabel 2

Muatan Faktor Skala MASQUE Versi Indonesia 3 Dimensi dengan Penghapusan 4 Item

\begin{tabular}{lc}
\multicolumn{1}{c}{ Item/Dimensi } & $\begin{array}{c}\text { Muatan } \\
\text { Faktor }\end{array}$ \\
$\begin{array}{lc}\text { Cronbach } \\
\text { Alpha }\end{array}$ \\
\hline Dimensi: Know & 0,539 \\
1. Saya menyadari bahwa rasisme terjadi di sekitar saya & 0,578 \\
2. Saya menyadari adanya batasan sosial & 0,846 \\
3. Saya memahami bahwa kepercayaan agama bisa berbeda-beda & 0,709 \\
4. Saya memahami bahwa kecenderungan seksual bisa berbeda-beda & 0,674 \\
5. Saya memahami adanya ketidakadilan terhadap perempuan & 0,810 \\
6. Saya menerima kenyataan bahwa terdapat bahasa selain bahasa Indonesia yang digunakan & 0,920 \\
Dimensi: Care & 0,803 \\
7. Saya menganggap penting untuk menghormati perbedaan agama & 0,862 \\
8. Saya peka terhadap perbedaan perilaku berdasarkan budaya & 0,810 \\
9. Saya prihatin secara emosional terhadap ketidakadilan etnis & 0,659 \\
10. Saya peka terhadap perbedaan status ekonomi & 0,900 \\
11. Status sosial seseorang tidak mempengaruhi perlakuan saya terhadap orang lain & 0,753 \\
Dimensi: Act & 0,866 \\
12. Saya tidak melakukan apa-apa untuk menghentikan ketidakadilan berdasarkan etnis & 0,773 \\
13. Saya tidak melakukan apa-apa untuk secara aktif melawan prasangka beragama & 0,490 \\
14. Saya tidak melakukan apa pun ketika menyaksikan perlakuan tidak adil berdasarkan &
\end{tabular}




\section{Gambar 1}

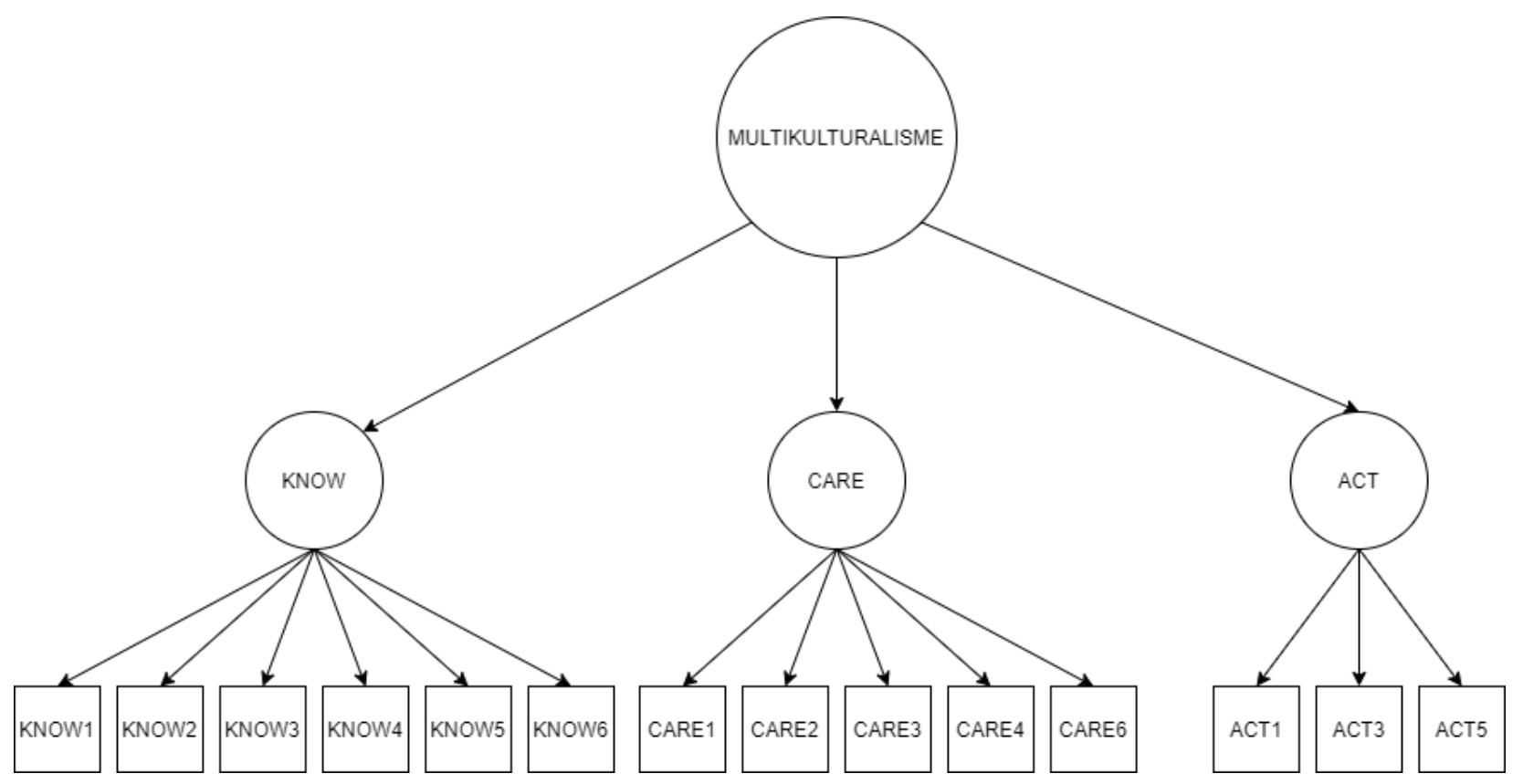

Berdasarkan hasil anal isis dapat disimpulkan bahwa dengan tidak menyertakan empat item yang memiliki faktor loading negatif, al at ukur dengan tiga dimensi dan 14 item menjadi fit dan reliabel.

\section{Diskusi}

Alat ukur MASQUE merupakan alat ukur multidimensional dengan tiga dimensi yaitu dimensi Know (Pengetahuan), Care (Kepedulian), dan Act (Tindakan). Dari hasil adaptasi alat ukur MASQUE dan pengujian psikometri yang telah dilakukan penulis, alat ukur dengan item berjumlah 18 yang terbagi ke dalam tiga dimensi ini tidak memiliki model yang baik karena tidak memenuhi satupun kriteria model fit karena ada empat item yang memiliki nilai faktor loading negatif dan juga tidak sesuai dengan konteks indonesia.

Item kedua pada dimensi actyang berbunyi "Saya secara aktif menantang ketidakadilan terhadap perempuan" tidak valid karena negara Indonesia masih mendukung penerapan konsep patriarki (paham yang mengutamakan laki-laki dan menganggap laki-laki memiliki status yang lebih tinggi daripada perempuan) dalam berbagai bidang seperti bidang ekonomi, sosial dan buday a sehingga terjadilah pembagian tugas berdasarkan gender dalam masyarakat Indonesia (Kercheval, dkk., 2013), sehingga ketidakadilan terhadap perempuan dianggap sebagai hal yang lumrah dan sudah seharusnya terjadi (Imron, Pramesti \& Wahyuni, 2017).

Item kelima pada dimensi care yang berbunyi "Saya tidak peka terhadap penggunaan bahasa selain bahasa Indonesia" tidak valid jika digunakan di Indonesia karena berbeda dengan status bahasa Inggris sebagai bahasa internasional dan banyak penggunanya yang merupakan monolingual, orang Indonesia sudah terbiasa menggunakan bahasa lain selain bahasa nasional Indonesia. Multilingualisme di Indonesia telah mengakar mengingat Indonesia merupakan bangsa yang terdiri dari keragaman kelompok etnis dan budaya serta telah terbiasa menggunakan bahasa daerah, bahasa Indonesia, dan bahasa asing dalam kehidupan sehari-hari (Nababan, 1991).

Item dari dimensi know yang tidak memenuhi kriteria adalah item yang berbunyi "Saya tidak mengerti kenapa masyarakat dari budaya lain berperilaku secara berbeda" tidak sesuai dengan masyarakat Indonesia yang telah terbiasa terpapar oleh beragam budaya. Indonesia telah menyadari tentang kemajemukan etnis dan budaya serta telah menjadikan multikulturalisme sebagai common platform yang berbasis Bhinneka Tunggal Ika (Azra, 2003). Nilai-nilai ini bahkan telah dimasukkan ke dalam mata pelajaran kewarganegaraan dan pendidikan agama yang telah menjadi mata pelajaran wajib sejak sekolah dasar.

Item yang berbunyi "Saya secara sopan membantu orang lain mengatasi batasan bahasa yang menghambat komunikasi" juga tidak valid, kemungkinan karena item ini rentan terhadap jawaban yang mengarah pada social desirability. Jika diberikan item tersebut, maka kecenderungan orang akan menjawab bahwa dia pasti membantu orang lain. Hal ini dibuktikan dengan jawaban responden 
yang lebih cenderung menjawab setuju (48\%), sangat setuju (23\%), dan agak setuju (14\%), sedangkan sisanya (15\%) menjawab tidak setuju.

Setelah dilakukan analisis ulang, validitas konstruk alat ukur tiga dimensi ini menjadi bagus. Selain itu, reliabilitas alat ukur secara keseluruhan maupun tiap dimensinya juga menjadi baik.

Meskipun studi ini telah menghasilkan alat ukur dengan validitas konstruk yang baik, tetapi studi ini memiliki beberapa keterbatasan. Pertama, adanya ketimpangan komposisi gender dengan dominasi perempuan. Kedua, uji validitas hanya menggunakan satu teknik saja. Keterbatasan ketiga, adanya empat item yang tidak sesuai dengan konteks indonesia dan sulit untuk dipahami oleh masyarakat Indonesia, sehingga ketika dihapus, model alat ukurnya menjadi fit dan alat ukur menjadi lebih valid. Tahap analisis selanjutnya kamilakukan untuk menjawab beberapa keterbatasan dalam studi 1 .

\section{Studi 2}

\section{Metode Penelitian}

\section{Partisipan, Desain, dan Prosedur}

Studi 2 dilakukan untuk menguji validitas diskriminan alat ukur MASQUE versi Indonesia serta untuk mengatasi kelemahan komposisi genderyang tidak rata pada studi sebelumnya. Validitas diskriminan diuji dengan mengorelasikan alat ukur MASQUE dengan skala Social Dominance Orientation (SDO) yang telah diadaptasi ke dalam bahasa Indonesia oleh Arifianto (2017). Multikulturalisme sebelumnya telah ditemukan memiliki korelasi negatif dengan SDO (Levin, dkk., 2012). Korelasi negatif ini dikarenakan multikulturalisme merupakan ideologi yang menentang adanya hierarki dalam sistem dan mendukung kesamaan status dalam sistem, sedangkan SDO merupakan orientasi individu yang cenderung mendukung adanya hierarki dalam sistem dan menentang persamaan status (Sidanius \& Pratto, 2012). Oleh karena itu, apabila individu memiliki skor yang tinggi pada skala multikulturalisme, maka dia cenderung akan memiliki skor rendah pada skala SDO. Sedangkan orang yang memiliki SDO tinggi merupakan orang-orang yang cenderung memiliki skor rendah pada skala multikulturalisme.

Pengisian kuesioner dilakukan secara daring pada Google Forms dan responden yang dijadikan sampel harus memenuhi kriteria WNI berusia di atas 18 tahun. Pertimbangan pemilihan usia karena pada usia 18 tahun individu telah memiliki pemahaman tentang multikulturalisme. Penyebaran skala ini juga dilakukan secara bersamaan dengan skala-skala lain yang digunakan untuk penelitian lain.

Pada tampilan pertama kuesioner, partisipan diberikan informed consent untuk menunjukkan kesediaannya berpartisipasi dalam penelitian. Pada halaman selanjutnya, partisipan diminta untuk mengisi data demografis seperti nama atau inisial, usia, asal daerah, agama, suku, bahasa, pekerjaan, dan pendidikan terakhir. Setelahnya, responden mengisi skala MASQUE versi Indonesia yang telah diadaptasi sebelumnya, dilanjutkan dengan skala SDO versi Indonesia. Responden diberi kesempatan untuk mengikuti undian pemberian hadiah berupa saldo uang elektronik sebesar Rp50.000,00 jika berkenan mencantumkan nomor ponsel yang kerahasiaannya dijaga oleh peneliti. Hanya responden yang menyetujui informed consent yang dapat melanjutkan pengisian kuesioner. Selain itu, hanya responden yang melengkapi semua data dan respon seluruh item kuesioner yang dimasukkan ke dalam sampel akhir yang akan dianal isis.

\section{Hasil Penelitian}

Jumlah responden dalam studi ini adalah 253 dengan komposisi $62,1 \%$ perempuan dan mayoritas beragama Islam ( $\mathrm{n}=198,78,3 \%)$. Rerata usia responden 25,24 tahun. Adapun status sosio-ekonomi responden pada studi ini memiliki tingkat pendidikan yang cukup tinggi, dengan $62,8 \%$ responden telah menyelesaikan S1, kemudian $24,9 \%$ responden telah menyelesaikan SMA, dan 22,5\% merupakan mahasiswaS1.

Hasil pengujian validitas alat ukur MASQUE versi Indonesia dengan menggunakan CFA untuk menguji validitas konstruk dan korelasi dengan skala SDO untuk menguji validitas diskriminan. CFA dilakukan dengan structural equation modeling (SEM) menggunakan package lavaan ver. 0.6-5 pada program R versi 3.6.2. Sebelum dilakukan uji CFA maka dilakukan uji normalitas dan hasilnya menunjukkan distribusi data tidak normal $(p<0,01)$. Oleh karena itu, dengan mempertimbangkan normalitas data dan jumlah sampel, maka digunakanlah estimator WLSMV yang bisa digunakan untuk data yang tidak normal dengan jumlah responden di bawah 300 .

Indeks fit yang digunakan sebagai kriteria penentu sama dengan studi sebelumnya yaitu: $\mathrm{CFI}>$ 0,95; RMSEA < 0,06 dan SRMR < 0,08 (Hu \& Bentler, 1999). Hasilnya model fit $\left(\chi^{2}(253)=194,570, \mathrm{p}<\right.$ $0,001, \mathrm{CFI}=0,959$, RMSEA $=0,0036$ [90\% CI 0,011; $0,054], \operatorname{SRMR}=0,1$ ) karena telah memenuhi dua dari tiga indikator yang ada yaitu CFI dan RMSEA. 
Tabel 3

Muatan Faktor Skala MASQUEversi Indonesia 3 Dimensi dengan Penghapusan 4 Item

\begin{tabular}{lc}
\multicolumn{1}{c}{ Item/Dimensi } & $\begin{array}{c}\text { Muatan } \\
\text { Faktor }\end{array}$ \\
$\begin{array}{lc}\text { Cronbach } \\
\text { Alpha }\end{array}$ \\
\hline Dimensi: Know & 0,7188 \\
1. Saya menyadari bahwa rasisme terjadi di sekitar saya & 0,738 \\
2. Saya menyadari adanya batasan sosial & 0,391 \\
3. Saya memahami bahwa kepercayaan agama bisa berbeda-beda & 0,753 \\
4. Saya memahami bahwa kecenderungan seksual bisa berbeda-beda & 0,738 \\
5. Saya memahami adanya ketidakadilan terhadap perempuan & 0,314 \\
6. Saya menerima kenyataan bahwa terdapat bahasa selain bahasa Indonesia yang digunakan & 0,466 \\
Dimensi: Care & 0,620 \\
7. Saya menganggap penting untuk menghormati perbedaan agama & 0,685 \\
8. Saya peka terhadap perbedaan perilaku berdasarkan budaya & 0,492 \\
9. Saya prihatin secara emosional terhadap ketidakadilan etnis & 0,436 \\
12. Saya peka terhadap perbedaan status ekonomi & 0,76 \\
13. Status sosial seseorang tidak mempengaruhi perlakuan saya terhadap orang lain & 1,024 \\
Dimensi: Act & 0,885 \\
14. Saya tidak melakukan apa-apa untuk menghentikan ketidakadilan berdasarkan etnis & 0,861 \\
15. Saya tidak melakukan apa-apa untuk secara aktif melawan prasangka beragama & 0,705 \\
16. Saya tidak melakukan apa pun ketika menyaksikan perlakuan tidak adil berdasarkan & \\
orientasi seksual & \\
\hline
\end{tabular}

Dapat dilihat dalam tabel di atas, tiap item pada semua dimensi memiliki faktor loading yang bagus, yakni lebih dari 0,3. Selain itu, setelah diuji reliabilitasnya, dapat disimpulkan bahwa skala memiliki reliabilitas yang baik dengan rentang Cronbach Alpha tiap dimensi antara 0,705-0,76. Selain memiliki validitas konstruk dan reliabilitas yang bagus, hasil validitas diskriminan juga menunjukkan bahwa alat ukur memiliki validitas diskriminan yang baik karena hasil korelasi dengan skala SDO versi Indonesia signifikan.

\section{Diskusi}

Studi 2 dilakukan untuk mengatasi beberapa batasan dalam studi 1 dan melakukan uji validitas ulang pada item-item yang dinyatakan baik pada studi 1 . Setelah menghapus beberapa item yang tidak memenuhi kriteria muatan faktor minimal pada studi 1 , CFA skala MASQUE pada studi 2 mengindikasikan nilai indeks fit yang baik $\left(\chi^{2}(253)=194,570, p<0,001\right.$, $\mathrm{CFI}=0,959$, RMSEA $=0,0036$ [90\% CI 0,011; 0,054], SRMR $=0,1$ ).

Selain dilakukan uji validitas konstruk, dilakukan juga uji validitas diskriminan dengan mengorelasikan MASQUE dengan skala Social Dominance Orientation (SDO). Sejalan dengan hasil analisis validitas konstruk studi 1, skala MASQUE tanpa 4 item memenuhi kriteria indeks fit yang baik. Selain itu, alat ukur ini memiliki validitas diskriminan yang bagus, karena setelah dikorelasikan dengan skala SDO yang memiliki konstruk yang bertolak belakang dengan multikulturalisme, alat ukur multikulturalisme ini menunjukkan hasil yang negatif dan signifikan. Hal ini menunjukkan bahwa alat ukur ini mengukur konstruk yang berbeda dengan SDO, sesuai dengan penelitian dan teori sebelumnya mengenai SDO dan multikulturalisme.

\section{Kesimpulan}

Kami melakukan 2 studi untuk menguji validitas dan reliabilitas Munroe Multicultural Attitude Scale Questionnaire (MASQUE) yang melalui proses adaptasi ke dalam bahasa Indonesia dengan tiga dimensi, yang terdiri dari dimensi know (pengetahuan), care (kepedulian), dan act (tindakan). Studi 1 mengindikasikan alat ukur MASQUE memiliki validitas yang buruk karena beberapa item memiliki muatan faktor yang rendah. Selain itu, studi 1 juga memiliki beberapa batasan, seperti komposisi responden yang timpang antara laki-laki dan perempuan. Untuk mengatasi batasan ini dan memperkuat validitas alat ukur, studi 2 dilakukan dengan menyebarkan alat ukur pada komposisi responden yang lebih setara dan mengorelasikan MASQUE dengan Social Dominance Orientation (SDO). Hasil analisis menemukan bahwa, setelah menghapus empat item dengan muatan faktor rendah, alat ukur MASQUE memiliki validitas konstruk yang baik dan validitas diskriminan yang baik.

Tim peneliti memutuskan untuk menghapus beberapa item yang tidak memenuhi kriteria item yang baik. Akan tetapi, karena konsep multikulturalisme sangat kontekstual, maka untuk penelitian selanjutnya yang ingin mengadaptasi alat ukur ini dan tidak ingin membuang item yang ada, maka kami sarankan untuk memodifikasi item-item tersebut sesuai dengan konteks budaya setempat. 


\section{Daftar Pustaka}

Amin, M. Z. M.,Wahab, D. A., \& Aziz, N. A. (2012). The level of multicultural awareness among english language teachers in Besut, Terengganu.

Arifianto, M. H. T. (2017). Orientasi dominasi sosial sebagai alternatif untuk melihat sikap implisit terhadap sistem sosial yang timpang: Adaptasi skala orientasi dominasi sosial7 (SD07 scale). Jurnal Psikologi Sosial, 15(2), 105-121.

https://doi.org/10.7454/jps.2017.10

Azra, Azyumardi. (2003). Pendidikan multikultural: Membangun kembali Indonesia Bhineka Tunggal Ika. Tsaqafah 1 (2).

Banks, J. A. (1999). An introduction to multicultural education (2nd ed.). Needham Heights, MA: Allyn \& Bacon.

Banks, J. A., \& Banks, C. A. M. (Eds.). (1995). Handbook of research on multicultural education. New York: Macmillan.

BBC.co.uk. (June $\left.28^{\text {th }}, 2004\right)$. Indonesia flashpoints: Kalimantan. Diunduh dari http://news.bbc.co.uk/2/hi/asiapacific/3811219.stm

Beaton, D. E., Bombardier, C., Guillemin, F., \& Ferraz, M. B. (2000). Guidelines for the process of cross-cultural adaptation of self-report measures. Spine, 25(24), 3186-3191. doi: 10.1097/00007632-200012150-00014

Benet-Martínez, V., \& Hong, Y. Y. (Eds.). (2014). The Oxford handbook of multicultural identity. Oxford University Press, USA. https://doi.org/10.1093/oxfordhb/9780199 796694.001 .0001

Berry, J. W., \& Kalin, R. (1995). Multicultural and ethnic attitudes in Canada: An overview of the 1991 national survey. Canadian Journal of Behavioural Science/Revue canadienne des sciences du comportement,27(3), 301. https://doi.org/10.1037/0008400x.27.3.301

BPS. Mengulik data suku di Indonesia. Diunduh dari https://www.bps.go.id/news/2015/11/18/1 27/mengulik-data-suku-di-indonesia.html

Enger, K., \& Lajimodiere, D. (2011). A multi-cultural transformative approach to learning. Multicultural Education \& Technology Journal.

Fishbein, M., \& Ajzen, I. (1975). Intention and Behavior: An introduction to theory and research.

Hoon, C. Y. (2017). Putting religion into multiculturalism: Conceptualising religious multiculturalism in Indonesia. Asian Studies Review, 41(3), 476-493. https://doi.org/10.1080/10357823.2017.13 34761

Hu, L. T., \& Bentler, P. M. (1999). Cutoff criteria for fit indexes in covariance structure analysis: Conventional criteria versus new alternatives. Structural Equation Modeling, 6(1), 1-55. https://doi.org/10.1080/107055199095401 18

Imron, A. H., Pramesti, M., \& Wahyuni, S. (2017). Why is Gender Inequality Still Appearing in Garment Factories in Indonesia? In International Conference on Business and Management Research (ICBMR2017). Atlantis Press. https://doi.org/10.2991/icbmr17.2017.24

Jensen, B., Whiting, E. F., \& Chapman, S. (2016). Measuring the multicultural dispositions of preservice teachers. Journal of Psychoeducational Assessment, 1-16. https://doi.org/10.1177/073428291666242 6

Kementerian Pendidikan dan Kebudayaan. (2018). Badan Bahasa petakan 652 bahasa daerah di Indonesia. Diunduh dari https://www.kemdikbud.go.id/main/blog/2 018/07/badan-bahasa-petakan-652-bahasadaerah-di-indonesia

Kercheval, J., Markowitz, D., Monson, K., \& Read, B. (2012). Women in leadership: Research on barriers to employment and decent work for women. Jakarta: International Labour Organization.

Levin, S., Matthews, M., Guimond, S., Sidanius, J, Pratto, F., Kteily, N., Pitpitan, E. V., \& Dover, T. (2012). Assimilation, multiculturalism, and colorblindness: Mediated and moderated relationships between social dominance orientation and prejudice.Journal of Experimental Social Psychology,48(1), 207212. https://doi.org/10.1016/j.jesp.2011.06.019

Munroe, A., \& Pearson, C. (2006). The Munroe multicultural attitude scale questionnaire: A new instrument for multicultural studies. Educational and Psychological Measurement, 66(5), 819-834 https://doi.org/10.1177/001316440528554 2

Nababan, P. W. J. (1991). Language in education: The case of Indonesia. International Review of $\begin{array}{llll}\text { Education } & 37 & \text { (1), 115-131. }\end{array}$ https://doi.org/10.1007/bf00598171

Rios, K., \& Wynn, A. N. (2016). Engaging with diversity: Framing multiculturalism as a learning opportunity reduces prejudice among high White American identifiers. European Journal of Social Psychology, 46(7), 854-865. https://doi.org/10.1002/ejsp.2196 
Parker, L. (2014). Religious Education for Peaceful Coexistence in Indonesia? South East Asia Research, 22(4), 487-504. https://doi.org/10.5367/sear.2014.0231

Parker, L. (2017). Intersections of Gender/Sex, Multiculturalism and Religion: Young Muslim Minority Women in Contemporary Bali. Asian Studies Review, 41(3), 441-458. https://doi.org/10.1080/10357823.2017.13 32004

Rosseel, Y. (2012). lavaan: An R Package for Structural Equation Modelling human forearm during rhythmic exercise. Journal of Statistical Software, 48(2), 1-36. https://doi.org/10.18637/jss.v048.i0

Sasaki, S. J., \& Vorauer, J. D. (2013). Ignoring Versus Exploring Differences Between Groups: Effects of Salient Color-Blindness and Multiculturalism on Intergroup Attitudes and Behavior. Social and Personality Psychology Compass, 7(4), 246-259. https://doi.org/10.1111/spc3.12021

Schroeder, J. L., Plata, M., Fullwood, H., \& Price, M. (2013). Increasing the cultural competence of assessment professionals via Online Training National Forum of Multicultural Issues Journal 10 (1), 1-13.

Sidanius, J. \& Pratto, F. (2012). Social Dominance Theory. In P. A. M. Van Lange, A. W. Kruglanski, \& E. T. Higgins (Eds). Handbook of Theories of Social Psychology (Vol. 2, pp. 399417). London: SAGE Publication, Ltd. https://doi.org/10.4135/9781446201022
Spiers, S., Gundala, R. R., \& Singh, M. (2014). Culture and consumer behavior: A study of Trinidad \& Tobago and Jamaica. International Journal of Marketing Studies 6 (4), 92-99. https://doi.org/10.5539/ijms.v6n4p92

Stuart, J., \& Ward, C. (2018). Exploring Everyday Experiences of Cultural Diversity: The Construction, Validation and Application of the Normative Multiculturalism Scale. European Journal of Social Psychology. https://doi.org/10.1002/ejsp.2542

Thornson, C. A., \& Ross, K. G. (2008). Identification of measures related to cross cultural competence. Defense Equal Opportunity Management Institute: Directorate of Research. https://doi.org/10.21236/ada488007

Van Camp, D., \& Baugh, S. (2016). Encouraging civic knowledge and engagement: Exploring current events through a psychological lens. Journal of the Scholarship of Teaching and $\begin{array}{llll}\text { Learning } & 16 & \text { (2), }\end{array}$ https://doi.org/10.14434/josotl.v16i2.1919 9

Van de Vijver, F. J., Breugelmans, S. M., \& SchalkSoekar, S. R. (2008). Multiculturalism: Construct validity and stability. International Journal of Intercultural Relations, 32(2), 93104. https://doi.org/10.1016/j.ijintrel.2007.11.00 